\title{
Documentos tipo obligatorios: ¿supresión de la potestad discrecional para la confección del pliego de condiciones? ${ }^{1}$
}

\author{
Cristian Andrés DíAz DíEZ²
}

\section{RESUMEN}

El artículo 4 de la Ley 1882 de 2018 estableció que el Gobierno Nacional debe adoptar pliegos de condiciones tipo obligatorios para ciertos procedimientos de selección contractual. Adicionalmente, lo facultó para crear y extender la obligatoriedad de dichos documentos a otras modalidades de selección. A partir de esta disposición y de los reglamentos expedidos por el Gobierno, se faculta a la Agencia Nacional de Contratación Pública -Colombia Compra Eficiente para implementar pliegos vinculantes para las entidades sometidas al Estatuto General de Contratación de la Administración Pública. En razón de estas competencias, surge la duda de si ha desaparecido la potestad discrecional

1 El presente artículo constituye el resultado del proyecto de investigación "Naturaleza y forma de garantía de la transparencia en el ejercicio de la función administrativa en Colombia", aprobado dentro de la convocatoria de proyectos con financiación interna 2018, de la Universidad EAFIT, en el que el autor es investigador responsable.

2 Magíster en Derecho de la Universidad de Antioquia, Medellín, Colombia. Profesor e investigador de tiempo completo de la Escuela de Derecho de la Universidad EAFIT, Medellín, Colombia. Correo-e: cdiazdi@eafit.edu.co. Enlace ORCID: 0000-0001-9139-6941. Fecha de recepción: 2 de marzo de 2020. Fecha de modificación: 10 de abril de 2020. Fecha de aceptación: 2 de mayo de 2020. Para citar el artículo: DíAz DíEz, CRISTIAN ANDrÉS, "Documentos tipo obligatorios: ¿supresión de la potestad discrecional para la confección del pliego de condiciones?", Revista digital de Derecho Administrativo, Universidad Externado de Colombia, n. ${ }^{\circ} 24,2020$, pp. 127-159. DOI: https://doi.org/10.18601/21452946.n24.06. 
para la confección del pliego de condiciones; inquietud que aborda el presente artículo.

Palabras clave: pliego de condiciones, documentos tipo, acto administrativo, discrecionalidad administrativa.

\section{Mandatory Standard Bidding Documents: Suppression of Discretionary Power to Determine Procurement Specifications?}

\section{ABSTRACT}

Article 4 of Law 1882 of 2018 established that the national government must adopt mandatory tender specifications for certain contractual selection procedures. It also authorized the government to create and extend the obligatory nature of said documents to other selection modalities. Based on this provision and the regulations issued by the national government, the Public Procurement Agency (Colombia Compra Eficiente, CCE) is able to implement mandatory bidding specifications for agencies subject to the General Public Procurement Act. Given the regulatory powers of $\mathrm{CCE}$, this paper seeks to determine whether the discretion of contracting agencies for determining procurement specifications has been suppressed.

Keywords: Bid Specification, Mandatory Standard Bidding Documents, Administrative Act, Agency Discretion, Public Procurement.

\section{INTRODUCCIÓN}

Si bien la figura del pliego de condiciones tipo no resulta novedosa en la contratación estatal colombiana, ya que desde hace algunos años ciertas entidades estatales la han utilizado, en parte, acogiendo las recomendaciones de la Agencia Nacional de Contratación Pública -Colombia Compra Eficiente contenidas en los documentos estandarizados publicados por este organismo, es indudable que el mandato consagrado en el artículo 4 de la Ley 1882 de 2018, que obliga al Gobierno Nacional a adoptar pliegos de condiciones tipo para algunos procedimientos de selección, con carácter vinculante para las entidades estatales sometidas al Estatuto General de Contratación de la Administración Pública, ha supuesto un cambio de paradigma ${ }^{3}$ en la forma de concebir la confección del pliego de condiciones. Esto, al menos en los procedimientos de selección en los que tales documentos tipo se han tornado 
obligatorios -en las licitaciones y selecciones abreviadas de menor cuantía para los contratos de obra pública de infraestructura de transporte, que son las modalidades en las cuales se han implementado hasta el momento-, las entidades estatales exhortadas a respetarlos han encontrado una restricción inusual en la elaboración del pliego de condiciones específico. De la existencia de enunciados normativos -como los previstos en las leyes 80 de 1993 y 1150 de 2007, así como en el Decreto 1082 de 2015-que les conferían una libertad considerable para determinar el contenido del pliego de condiciones, han observado cómo los pliegos tipo obligatorios les han restado significativamente dicho margen de configuración; con lo cual, la confección del pliego de condiciones para cada caso se ha tornado, en gran parte, para las entidades estatales en una labor consistente en "llenar" los espacios preestablecidos en el pliego modelo, en completar los formatos, en verificar que se cumpla lo que dispone cada numeral del documento estándar y en cerciorarse de que no se establezcan cláusulas que excedan las que permita el pliego tipo.

En tal sentido, la pregunta que aborda este artículo es si en aquellos eventos en los cuales el pliego de condiciones tipo es obligatorio para las entidades públicas desaparece su discrecionalidad para la confección del pliego de condiciones específico, es decir, del que debe acogerse al documento estándar. Para responder tal inquietud, en primer lugar, se analiza el concepto de acto administrativo producto de una potestad discrecional, lo que supone a su vez estudiar algunos de los principales aportes teóricos acerca del concepto de discrecionalidad administrativa y la elección del que se considera más oportuno para este escrito. En segundo lugar, se expone en qué medida el pliego de condiciones se ha caracterizado tradicionalmente como un acto administrativo discrecional, ello, sin perjuicio de la tesis actual de la Sección Tercera del Consejo de Estado y de un sector doctrinario, como más adelante se explicará, que considera que cuando el contrato estatal se perfecciona, el pliego de condiciones muta a clausulado contractual, perdiendo así su carácter de acto administrativo. En tercer lugar, se estudia la figura del pliego de condiciones tipo, indagando por su naturaleza jurídica, por los antecedentes de su introducción en el ordenamiento jurídico colombiano en respuesta a la tendencia de estandarización de los documentos en el sistema de contratación pública, por el alcance del mandato contenido en el artículo 4 de la Ley 1882 de 2018 y por algunas discusiones que se han presentado acerca de la competencia reglamentaria de la Agencia Nacional de Contratación Pública - Colombia Compra Eficiente en cuanto al desarrollo e implementación de los pliegos tipo. En cuarto lugar, se enfrenta el problema que motiva la elaboración de este texto, es decir, si en aquellos casos en los que el pliego de condiciones específico debe configurarse a partir de un pliego tipo, aquel debe considerarse un acto administrativo reglado o continúa siendo discrecional. 


\title{
1. ACTO ADMINISTRATIVO PRODUCTO DE POTESTAD DISCRECIONAL. ALGUNAS NOTAS SOBRE EL CONCEPTO DE DISCRECIONALIDAD ADMINISTRATIVA
}

\begin{abstract}
Dentro de la clasificación de los actos administrativos se halla el que es producto de una potestad discrecional ${ }^{4}$, por oposición al acto administrativo que se deriva del ejercicio de una potestad reglada. La diferencia principal entre ambos consiste en que, mientras el acto administrativo reglado es resultado de la única posibilidad de decisión válida por parte de la autoridad en el caso concreto ${ }^{5}$, el acto administrativo discrecional es aquel que emerge de la apreciación que efectúa la autoridad de los supuestos fácticos y jurídicos, escogiendo, entre varias opciones, la más acorde con el interés público.

Las definiciones de la discrecionalidad administrativa son múltiples ${ }^{6}$. Por una parte, se ha considerado que la discrecionalidad es la facultad de que goza la
\end{abstract}

4 En palabras de Raúl Bocanegra Sierra, según la naturaleza de la potestad ejercida por la autoridad, los actos administrativos pueden ser reglados o discrecionales. De este modo, define los actos administrativos reglados como aquellos que "se dictan con el contenido legalmente previsto cuando se da el supuesto de hecho que la norma establece, en una pura operación de constatación de cumplimiento de los requisitos establecidos en el ordenamiento", mientras que "en los actos administrativos discrecionales, la Administración decide, por razones de interés público, en el marco de los principios generales del derecho administrativo y teniendo en cuenta el fin de la norma habilitante, tanto si, ante una determinada situación, procede dictar un acto administrativo como, tomada la decisión de hacerlo, cuál sea el contenido del acto discrecional, optando entre las diversas opciones posibles, todas ellas igualmente válidas, que puedan presentarse". Raúl BocanEGRA SIERRA, Lecciones sobre el acto administrativo, 3ª. ed., Madrid: Thomson Civitas, 2006, p. 57. En similar sentido, véase Miguel S. MARIENHOFF, Tratado de derecho administrativo, t. II, Actos de la Administración pública, 4. ${ }^{a}$ ed., Buenos Aires: Abeledo-Perrot, 1993, pp. 413-414.

5 Miguel S. MarienHofF, Tratado de derecho administrativo, t. II, óp. cit., p. 415.

6 Sobre el concepto de discrecionalidad administrativa, véanse: CRISTIAN ANDrÉs Díaz DíEZ, La jurisdicción de lo contencioso administrativo. El control jurisdiccional especializado de la Administración pública dentro del Estado de derecho y la democracia, Medellín: Librería Jurídica Sánchez - Universidad de Antioquia - Centro de Estudios de Derecho Administrativo, 2013, pp. 325 388; Hugo Alberto Marín Hernández, Discrecionalidad administrativa, Bogotá: Universidad Externado de Colombia, 2007, pp. 139-288; Harmut Maurer, Derecho administrativo. Parte general, 17.a. ed., Madrid: Marcial Pons, 2011, pp. 165-191; José María RodríGueZ DE Santiago, Metodología del derecho administrativo. Reglas de racionalidad para la adopción y el control de la decisión administrativa, Madrid: Marcial Pons, 2016, pp. 149-196; Rodolfo Carlos BARRA, "Los actos administrativos coligados en el contrato administrativo", en Juan Carlos Cassagne (dir.), Tratado general de los contratos públicos, t. I, Buenos Aires: La Ley, 2013, pp. 225-235; EdUARDO GarCía DE ENTERRía, La lucha contra las inmunidades del poder en el derecho administrativo. Poderes discrecionales, poderes de gobierno, poderes normativos, 3. ${ }^{\text {a }}$ ed., Madrid: Civitas, 1995, pp. 24-49; EVA DeSDENTADO DAROCA, Los problemas del control judicial de la discrecionalidad técnica. Un estudio crítico de la jurisprudencia. Madrid: Civitas, 1997, pp. 19-28; Juan Gustavo CORVALÁN, Derecho administrativo en transición. Reconfiguración de la relación entre la Administración, las normas y el Poder Judicial. Reglas y principios. Discrecionalidad débil y fuerte. Valoración, interpretación y ponderación. Control judicial y políticas públicas, Buenos Aires: Astrea, 2016, pp. 69-138; 
Administración para valorar el interés público en cada caso, determinando la mejor forma de satisfacerlo. De otro lado, se ha entendido que es la libertad para escoger una opción entre varias que tienen igual validez. Según Marín Hernández, el primero de tales conceptos hace parte de las denominadas definiciones "materiales" o "positivas" de la discrecionalidad administrativa, mientras que el segundo se ubica dentro de las definiciones "formales" o "negativas". En efecto, como lo explica dicho autor, las primeras son aquellas que definen la discrecionalidad administrativa como la libertad que concede el ordenamiento jurídico a la Administración para apreciar en cada caso en qué consiste el interés público y valorar la mejor forma de satisfacerlo, a partir de la ponderación de derechos, valores, intereses, medidas, hechos, criterios técnicos, económicos, etc.; mientras que las definiciones formales son aquellas que conceptualizan la discrecionalidad administrativa como la libertad conferida por el sistema normativo para escoger cualquiera de las opciones de decisión, por ser todas igualmente viables ${ }^{7}$.

Lo cierto es que la discrecionalidad administrativa es una potestad que otorga a las autoridades un alto, aunque relativo ${ }^{8}$, margen de apreciación o de libertad para la toma de decisiones, ya que, contrario a lo que sucede con la potestad

Juan Carlos Cassagne, El principio de legalidad y el control judicial de la discrecionalidad administrativa, Madrid: Marcial Pons, 2009, pp. 173-217.

7 Hugo Alberto Marín Hernández, "Naturaleza jurídica de las facultades de la Administración para confeccionar pliegos de condiciones", Revista digital de Derecho Administrativo, n. ${ }^{\circ}$ 1, Universidad Externado de Colombia, 2009, pp. 8-9. Este autor rechaza las definiciones negativas, por considerar que contrarían el modelo de Estado social y democrático de derecho, ya que en este sistema la Administración no puede gozar de libertad absoluta para decidir, sino que debe hacerlo siempre como gestora del interés general, justificando cuál es la opción más razonable para garantizarlo (p. 10); tesis que se comparte.

8 Actualmente no puede admitirse una discrecionalidad absoluta, que se confunda con la arbitrariedad, sino una libertad limitada por el bloque de juridicidad. Ibíd., pp. 11-12. En igual sentido, véase Miguel S. MarienHOFF, Tratado de derecho administrativo, t. II., óp. cit., p. 418. La Corte Constitucional ha reconocido el carácter limitado de la discrecionalidad administrativa. En tal sentido, ha indicado que esta no puede asimilarse a la arbitrariedad, pues aquella tiene límites en el Estado social y democrático de derecho (Corte Constitucional, sentencias: C-071 del 23 de febrero de 1994, expediente D-380; C-918 del 29 de octubre de 2002, expediente D-3996; T-288 del 4 de junio de 1998, expediente T-156679, C-734 del 21 de junio de 2000, expediente D-2732; T-1094 del 5 de diciembre de 2002, expediente T-592228; C-553 del 6 de julio de 2010, expediente D-7951; T-686 del 11 de septiembre de 2014, expediente T-4.346.728 y SU-172 del 16 de abril de 2015, expediente T-4.076.348, entre otras. Así mismo, el Consejo de Estado ha indicado en repetidas ocasiones que la confección del pliego de condiciones es una potestad administrativa que tiene límites, porque las entidades estatales no pueden introducir cláusulas que menoscaben principios como la libre concurrencia, la transparencia, la selección objetiva, etc., o causales de rechazo desproporcionales. Al respecto, véase: Consejo de Estado, Sección Tercera: sentencia del 25 de octubre de 2019, radicación 66001-23-31-000-2004-00668 02, expediente 37862 y sentencia del 5 de agosto de 2019, radicación 25000-23-26-0002009-00264-01, expediente 45118. 
reglada, las condiciones, el contenido y el procedimiento de la decisión no se hallan predeterminados en la premisa mayor del enunciado normativo. En tal ámbito discrecional, la operación argumentativa se basa en razonamientos de diversa índole, es decir, no solo jurídicos, sino también técnicos, económicos y políticos, entre otros, que se reconducen a la valoración de la oportunidad o conveniencia ${ }^{9}$. De ahí que, desde una concepción mixta -no circunscrita a las definiciones materiales o a las formales-, como la propugnada por Marín Hernández y que se comparte en el presente texto, deba decirse que actualmente la discrecionalidad administrativa es la libertad para completar el supuesto fáctico contenido en el enunciado normativo, para determinar cuándo actuar y para escoger la mejor opción decisoria que garantice el interés general, con criterios razonables y motivados.

\section{PLIEGO DE CONDICIONES: SU CARACTERIZACIÓN COMO ACTO ADMINISTRATIVO DISCRECIONAL Y LA TESIS DE LA DOBLE NATURALEZA JURÍDICA}

El pliego de condiciones es una institución jurídica que ostenta doble naturaleza. Nace como un acto administrativo de carácter general ${ }^{10}$, que establece

9 Miguel s. MARIENHOFF, Tratado de derecho administrativo, t. II, óp. cit., pp. 416-418.

10 Así lo ha reconocido el Consejo de Estado. Al respecto véase: Consejo de Estado, Sección Tercera: sentencia del 31 de mayo de 2019, radicación 11001-03-26-000-2010-00077-00, expediente 39961; auto del 19 de julio de 2018, radicación 11001-03-26-000-2017-0015100, expediente 60291; sentencia del 27 de noviembre de 2017, radicación 08001-23-31000-1998-02160-01, expediente 58362 y sentencia del 2 de marzo de 2017, radicación 25000-23-26-000-1997-03892-01, expediente 36442. Se trata, pues, de uno de los actos administrativos que preceden la celebración del contrato, pues " $\mathrm{El}$ [...] contrato llega a través de un largo procedimiento que está integrado de actos administrativos sucesivos (iniciación del expediente de contratación, aprobación del pliego de cláusulas, fiscalización de la existencia de crédito presupuestario y autorización del gasto, aprobación del proyecto de la obra)". Gaspar Ariño Ortiz, "El enigma del contrato administrativo", en Juan Carlos Cassagne (dir.), Tratado general de los contratos públicos, t. I, Buenos Aires: La Ley, p. 68. La Corte Constitucional ha definido el pliego de condiciones como un acto administrativo de carácter general en las sentencias: SU-713 del 23 de agosto de 2006, expediente T-851356 y T-373 del 11 de mayo de 2007, expediente T-1535128. En similar sentido, véase la doctrina de Ernesto Matallana Camacho, "La preservación de las garantías constitucionales en la licitación en el trámite de evaluación de las propuestas y el control que ejerce el juez sobre la actividad contractual de la Administración pública", en Julián Andrés Pimiento Echeverri (ed.), Las transformaciones de la Administración pública y del derecho administrativo, t. III, Las dimensiones del control sobre la actividad administrativa, Bogotá: Universidad Externado de Colombia, 2019, p. 85. Sin embargo, la consideración del pliego de condiciones como acto administrativo no es pacífica. Verbigracia, Dromi define el acto administrativo como la "declaración unilateral efectuada en el ejercicio de la función administrativa, que produce efectos jurídicos individuales en forma directa". ROBERTO DrOMI, Acto administrativo, 4. a ed., Buenos Aires: Ediciones Ciudad Argentina, Madrid - México: Hispania Libros, 2008, p. 37. A su vez, indica que el reglamento administrativo es "toda declaración unilateral efectuada 
las reglas del procedimiento de selección y del futuro contrato y, al perfeccionarse, se convierte en clausulado contractual ${ }^{11}$. En tal medida, se ha calificado como la ley del procedimiento de selección y del contrato ${ }^{12}$ o como "hoja de ruta o plan de navegación sobre el cual se diseña, estructura y concreta el denominado proceso contractual de la Administración pública"13. Sin embargo, un sector de la doctrina considera que el hecho de que se celebre el contrato

en ejercicio de la función administrativa que produce efectos jurídicos generales en forma directa" (p. 275). Bajo tales definiciones, el pliego de condiciones podría considerarse un reglamento, tesis que, como se verá, solo puede predicarse hoy en Colombia del pliego de condiciones tipo obligatorio.

11 En efecto, el Consejo de Estado plantea que el pliego de condiciones tiene una doble naturaleza jurídica: "Por una parte, antes de la adjudicación del contrato, constituyen un acto administrativo de carácter general y sus reglas son de obligatorio cumplimiento para la Administración y para los oferentes que acudan al proceso. Pero, una vez celebrado el contrato, lo dispuesto en el pliego se convierte en el marco jurídico que determina el contenido y alcance del negocio jurídico acordado". Consejo de Estado, Sección Tercera, sentencia del 31 de mayo de 2019, radicación 11001-03-26-000-2011-00065-00, expediente 42282. En similar sentido, véase: Consejo de Estado, Sección Tercera: auto del 2 de abril de 2019, radicación 11001-03-26-000-2018-00097-00, expediente 61964 y sentencia del 30 de julio de 2015, radicación 25000-23-26-000-1997-13723-01, expediente 29942). En la misma línea, el alto tribunal ha indicado que el pliego de condiciones se incorpora al contrato, de modo que si se presenta una contradicción entre estos, prevalece el pliego. Consejo de Estado, Sección Tercera, sentencia del 3 de septiembre de 2015, radicación 25000-23-26-000-2002-01433-01, expediente 33790. Por su parte, Marienhoff expresa que el pliego de condiciones es "el conjunto de documentos escritos que determinan las condiciones del contrato". Miguel S. MarienHoff, Tratado de derecho administrativo, t. III-A, Contratos administrativos. De los contratos en particular, 4. ${ }^{a}$ ed., Buenos Aires: Abeledo-Perrot, 1998, p. 209. En similar sentido, véanse: Miguel Ángel BerÇAITZ, Teoría general de los contratos administrativos, Buenos Aires: Depalma, 1980, pp. 329-334; Luis Guillermo Dávila VinueZa, Régimen jurídico de la contratación estatal, 3. ${ }^{a}$ ed., Bogotá: Legis, 2016, pp. 393-395.

12 Así lo ha dicho en diversas oportunidades el máximo tribunal de lo contencioso administrativo, al señalar que el pliego de condiciones es la "ley del procedimiento de selección y ley del futuro contrato", en la medida en que sus efectos irradian al negocio jurídico, es decir, van más allá del acto administrativo de adjudicación. Al respecto, véanse: Consejo de Estado, Sección Tercera: sentencia del 25 de octubre de 2019, radicación 25000-23-26000-2007-00677-01, expediente 39945; sentencia del 21 de septiembre de 2017, radicación 25000-23-26-000-2001-02144-01, expediente 37478 y sentencia del 30 de junio de 2016, radicación 25000-23-26-000-1998-02425-01, expediente 34652. También ha indicado que el pliego de condiciones tiene carácter vinculante para la entidad estatal, así como para los interesados, los proponentes y el contratista, quienes no pueden desconocer sus términos. Consejo de Estado, Sección Tercera: sentencia del 7 de diciembre de 2017, radicación 25000-23-26-000-2007-00059-01, expediente 41888; sentencia del 5 de abril de 2017, radicación 25000-23-26-000-2001-00309-01, expediente 35163B; y sentencia del 29 de febrero de 2016, radicación 25000-23-26-000-1999-02474-02, expediente 32141. Véase igualmente: Corte Constitucional, sentencia T-154 del 28 de abril de 1998, expediente T- 150254

13 Consejo de Estado, Sección Tercera, sentencia del 30 de septiembre de 2019, radicación 25000-23-26-000-2009-01040-01, expediente 46733. 
no le hace perder al pliego de condiciones su carácter de acto administrativo general, lo que permite afirmar su prevalencia sobre aquel ${ }^{14}$.

En ejercicio de la competencia atribuida por el inciso final del artículo 150 de la Constitución Política ${ }^{15}$, el legislador expidió la Ley 80 de 1993 -Estatuto General de Contratación de la Administración Pública-, cuerpo normativo que consagra enunciados que reconocen la discrecionalidad administrativa en la confección del pliego de condiciones, al tiempo que establece sus requisitos. En efecto, el artículo 24, numeral 5 de dicha Ley, modificado por el artículo 32 de la Ley 1150 de 2007, prescribe el contenido mínimo del pliego de condiciones, utilizando conceptos jurídicos indeterminados ${ }^{16}$, pues alude a términos como "requisitos objetivos necesarios", "reglas justas, claras y completas" o "escogencia objetiva", y encomienda a la entidad estatal su configuración ${ }^{17}$. Adicionalmente, el artículo 29 de la Ley 80 regulaba el deber de selección objetiva, haciéndolo depender de la sujeción de las ofertas a los factores de escogencia previstos en el pliego de condiciones. Sin embargo, esta norma fue derogada por el artículo 32 de la Ley 1150 de 2007, que, en su artículo 5, reemplazó la regulación de dicho postulado; disposición que ha tenido importantes cambios con la expedición de las leyes 1474 de 2011 y

14 ÉDGAR GONZÁLEZ LÓPEZ, El pliego de condiciones en la contratación estatal. La reforma consagrada en la Ley 1150 de 2007 y sus decretos reglamentarios, Bogotá: Universidad Externado de Colombia, 2010, p. 49. Sobre la naturaleza del pliego de condiciones consúltese también el siguiente texto: LeOnARDo F. MASSimo, "Los pliegos de bases y condiciones", en Juan Carlos Cassagne (dir.), Tratado general de los contratos públicos, t. II. Buenos Aires: La Ley, 2013, pp. 881-943.

15 Dicho inciso dispone: "Compete al Congreso expedir el estatuto general de contratación de la Administración pública y en especial de la Administración nacional".

16 Consejo de Estado, Sección Tercera, sentencia del 30 de diciembre de 2006, radicación 11001-03-26-000-2000-00020-01, expediente 18059.

17 El artículo 24, numeral 5. ${ }^{\circ}$ de la Ley 80 de 1993, con la modificación introducida por el artículo 32 de la Ley 1150 de 2007 establece: "En los pliegos de condiciones:

a) Se indicarán los requisitos objetivos necesarios para participar en el correspondiente proceso de selección.

b) Se definirán reglas objetivas, justas, claras y completas que permitan la confección de ofrecimientos de la misma índole, aseguren una escogencia objetiva y eviten la declaratoria de desierta de la licitación.

c) Se definirán con precisión las condiciones de costo y calidad de los bienes, obras o servicios necesarios para la ejecución del objeto del contrato.

d) No se incluirán condiciones y exigencias de imposible cumplimiento, ni exenciones de la responsabilidad derivada de los datos, informes y documentos que se suministren.

e) Se definirán reglas que no induzcan a error a los proponentes y contratistas y que impidan la formulación de ofrecimientos de extensión ilimitada o que dependan de la voluntad exclusiva de la entidad.

f) Se definirá el plazo para la liquidación del contrato, cuando a ello hubiere lugar, teniendo en cuenta su objeto, naturaleza y cuantía.

Serán ineficaces de pleno derecho las estipulaciones de los pliegos y de los contratos que contravengan lo dispuesto en este numeral, o dispongan renuncias a reclamaciones por la ocurrencia de los hechos aquí enunciados". 
1882 de 2018. Asimismo, el artículo 4 de la Ley 1150 de 2007 establece que el pliego de condiciones debe incluir la tipificación, estimación y asignación de los riesgos. Por su parte, el Decreto 1082 de 2015 alude al pliego de condiciones como uno de los documentos del proceso ${ }^{18}$, disponiendo su contenido mínimo $^{19}$. El pliego de condiciones determina las reglas aplicables tanto a la licitación pública, como a la selección abreviada y al concurso de méritos. En la contratación de mínima cuantía rige un documento equivalente, que la normativa denomina "invitación"20.

A partir de ello, puede decirse que el pliego de condiciones, como institución jurídica, es propio de los procedimientos de selección consistentes en una convocatoria pública o, expresado de otra manera, en una invitación plural realizada por un sujeto interesado en recibir ofertas. En consecuencia, no es exclusivo de la contratación estatal, pues el derecho privado también lo consagra, solo que bajo el nombre impropio de "pliego de $\operatorname{cargos}^{\prime 21}$. De ahí que el pliego de condiciones - en su acepción genérica, es decir, independientemente de la denominación que se le otorgue en cada caso- también exista -y de hecho se aplique- en la contratación efectuada por las entidades que se rigen por el derecho privado, es decir, por las que se exceptúan, en principio ${ }^{22}$, del Estatuto General de Contratación de la Administración Pública, pues también realizan llamados generales a presentar ofertas y deben regular dichas invitaciones de manera clara para garantizar el principio de selección objetiva ${ }^{23}$.

Decreto 1082 de 2015, artículo 2.2.1.1.1.3.1.

19 Decreto 1082 de 2015, artículo 2.2.1.1.2.1.3. Sobre el contenido mínimo del pliego de condiciones, véanse también: Consejo de Estado, Sección Tercera, sentencia del 30 de julio de 2015, radicación 25000-23-26-000-1997-13723-01, expediente 29942; LuIS GuILLERmo Dávila Vinueza, óp. cit., pp. 370-393; Juan David Duque Botero, Contratación pública estratégica, socialmente responsable y competitiva, Valencia: Tirant lo Blanch; Bogotá: Universidad del Rosario, 2018, p. 329

20 Ley 1150 de 2007, artículo 2, numeral 5.

21 El artículo 860 del Código de Comercio dice: "En todo género de licitaciones, públicas o privadas, el pliego de cargos constituye una oferta de contrato y cada postura implica la celebración de un contrato condicionado a que no haya postura mejor. Hecha la adjudicación al mejor postor, se desecharán las demás".

22 Se dice que se exceptúan en principio, porque el artículo 13 de la Ley 1150 de 2007 señala: "Las entidades estatales que por disposición legal cuenten con un régimen contractual excepcional al del Estatuto General de Contratación de la Administración Pública, aplicarán en desarrollo de su actividad contractual, acorde con su régimen legal especial, los principios de la función administrativa y de la gestión fiscal de que tratan los artículos 209 y 267 de la Constitución Política, respectivamente según sea el caso y estarán sometidas al régimen de inhabilidades e incompatibilidades previsto legalmente para la contratación estatal". Ello significa que, aunque una entidad estatal tenga un régimen especial de contratación, debe respetar la regulación sobre inhabilidades e incompatibilidades establecida en el Estatuto General de Contratación de la Administración Pública.

23 Así lo admitió el Consejo de Estado en sentencia del 10 de febrero de 2016, al expresar que el pliego de condiciones de las entidades exceptuadas de la aplicación del Estatuto 
Durante el procedimiento de selección, el pliego de condiciones es un acto administrativo discrecional ${ }^{24}$ porque es elaborado por parte de la Administración en ejercicio del margen de libertad relativa ${ }^{25}$ conferido por las disposiciones que establecen los contenidos mínimos de dicho acto y porque debe ser confeccionado por ella a partir de criterios objetivos que permitan la selección objetiva del futuro contratista-técnicos, jurídicos y económicos- ${ }^{26}$. Ahora bien, como debe suceder siempre que la Administración decida, al hacer el pliego de condiciones o su documento equivalente la entidad estatal debe respetar aquello que la doctrina del derecho administrativo ha denominado los "elementos reglados" ${ }^{127}$ de todo acto administrativo, que en el ordenamiento jurídico colombiano están previstos en el artículo 137 de la Ley 1437 de 2011 -que consagra los vicios que pueden afectar su validez-, así como los principios generales del derecho ${ }^{28}$.

General de Contratación de la Administración Pública es la oferta mercantil regulada en el artículo 860 del Código de Comercio. Consejo de Estado, Sección Tercera, sentencia del 10 de febrero de 2016, radicación 25000-23-26-000-2003-00959-01, expediente 38696.

24 Es discrecional en cuanto a su confección, pero, como ha indicado la jurisprudencia, por regla general, no en cuanto a su interpretación, porque una vez elaborado la entidad estatal debe aplicarlo de forma reglada y solo puede desentrañar su sentido con carácter discrecional para llenar vacíos contenidos en él. Consejo de Estado, Sección Tercera, sentencia del 18 de mayo de 2017, radicación 05001-23-31-000-2010-01243-01, expediente 54480. Así también lo admite la doctrina. Véase: ÉdGAR GonZÁLEZ LópeZ, óp. cit., p. 83.

25 El margen de libertad con que cuenta la Administración para hacer el pliego de condiciones, como se ha dicho, no es absoluto. Véase: Consejo de Estado, Sección Tercera, sentencia del 26 de noviembre de 2015, radicación 85001-23-31-000-2011-00109-01, expediente 51376 .

26 Hugo Alberto Marín Hernández, "Naturaleza jurídica de las facultades de la administración...", óp. cit., pp. 13-14.

27 "... en todo acto discrecional hay elementos reglados suficientes como para no justificarse de ninguna manera una abdicación total del control sobre los mismos. Estos elementos reglados son, por de pronto, la misma existencia de la potestad, de cuyo ejercicio dimana el acto, la extensión concreta de esta potestad, que es imposible que sea totalmente indeterminada, y, en fin, la competencia para ejercitarla. Estos son siempre elementos necesariamente reglados. Luego lo son normalmente, aunque pueden no darse o darse en distinta medida, las formas determinantes para el ejercicio de la potestad $y$, en fin, el fondo parcialmente reglado; puede haber, en efecto, una regulación, y además, ordinariamente la hay, no totalmente discrecional, sino parcialmente discrecional en cuanto al fondo, que obliga, pues, a considerar o a partir de ciertos elementos reglados previos". Eduardo García de EnTerría, óp. cit., pp. 25-26. En la misma línea, Hugo Alberto MaRín HERnÁNDEZ, "Naturaleza jurídica de las facultades de la administración...", óp. cit., p. 16. Así mismo, el Consejo de Estado ha planteado que, en la elaboración del pliego de condiciones y como parte de los elementos reglados, la Administración tiene una carga de claridad y precisión. Consejo de Estado, Sección Tercera, sentencia del 30 de julio de 2015, radicación 25000-23-26-000-1999-00242-01, expediente 25296 y sentencia del 28 de mayo de 2015, radicación 41001-23-31-000-1995-08008-01, expediente 29661.

28 Hugo Alberto Marín HernándeZ, "Naturaleza jurídica de las facultades de la administración...", óp. cit., p. 17. 
En tal sentido, la doctrina ${ }^{29}$ y la jurisprudencia ${ }^{30}$ han admitido que el pliego de condiciones es producto del ejercicio de una potestad discrecional por parte de la entidad estatal. Así mismo, ha precisado que la circunstancia de que las disposiciones normativas que regulan la confección del pliego de condiciones, fijando ciertos requisitos y límites, utilicen conceptos jurídicos indeterminados, no elimina la discrecionalidad que tienen las entidades estatales para su elaboración, porque dichos conceptos también son fuente de discrecionalidad, ya que en estos sigue existiendo un margen de apreciación, al menos en su zona de incertidumbre o vaguedad ${ }^{31}$.

En efecto, hasta la expedición de la Ley 1882 de 2018, las normas que regulaban la elaboración de los pliegos de condiciones en la contratación estatal se limitaban "a señalar criterios o parámetros generales ${ }^{1 / 32}$ que dejaban en manos de la Administración la definición de las reglas objetivas y razonables que gobernarían cada proceso de selección. A pesar de que ya había algunos intentos de estandarización que se estudiarán más adelante, lo cierto es que fue a partir de la mencionada ley que el derecho administrativo de la contratación estatal se abrió paso al establecimiento de documentos tipo obligatorios para la confección de los pliegos de condiciones; por lo que adquiere interés analizar si con la existencia de dichos instrumentos puede seguir afirmándose que la elaboración del pliego de condiciones es una potestad discrecional de las entidades estatales o por el contrario se ha convertido en una potestad reglada. Para responder esta cuestión, se harán algunos comentarios acerca del concepto y la naturaleza de los referidos documentos tipo.

\section{PLIEGO DE CONDICIONES TIPO}

\subsection{Concepto y nATURALEZA JURÍDicA}

El pliego de condiciones tipo es un documento mediante el cual se estandariza el contenido mínimo de los pliegos de condiciones que confeccionarán en el

29 Ibíd., pp. 1-18; Édgar GonZÁlez López, óp. cit., pp. 87-90; Juan David Duque Botero, óp. cit., pp. 268-270; Roberto Dromi, Licitación pública, 2. ${ }^{a}$ ed., Buenos Aires: Ediciones Ciudad Argentina, 1995, p. 246.

30 Entre otras providencias, pueden mencionarse las siguientes: Consejo de Estado, Sección Tercera: sentencia del 2 de agosto de 2018, radicación 25000-23-36-000-2013-0129301, expediente 53506A; sentencia del 3 de diciembre de 2015, radicación 76001-23-31000-2000-00785-01, expediente 31915; sentencia del 1. ${ }^{\circ}$ de octubre de 2015, radicación: 25000-23-26-000-2005-00214-01, expediente 34778; sentencia del 13 de agosto de 2014, radicación: 25000-23-26-000-2004-01200-01, expediente 35965 y auto del 30 de agosto de 2008, radicación: 70001-23-31-000-1997-06303-01, expediente 23003.

31 Hugo Alberto Marín HernándeZ, "Naturaleza jurídica de las facultades de la administración...", óp. cit., p. 7.

32 Ibíd., p. 6. 
futuro las entidades estatales con fundamento en aquel ${ }^{33}$. En tal sentido, conviene indagar por su naturaleza jurídica. Esta varía, según su grado de vinculación, es decir, dependiendo de si es obligatorio o facultativo. Así, mientras que el pliego tipo obligatorio tiene las notas de un reglamento ${ }^{34}$, el pliego tipo facultativo es un acto de la Administración -no un acto administrativorevestido del carácter de soft law ${ }^{35}$.

Se afirma que el pliego de condiciones tipo que vincula a los sujetos de la contratación estatal es un reglamento, en tanto se trata de un acto administrativo general, expedido en ejercicio de la función administrativa, que, además, innova el ordenamiento jurídico y goza de vocación de permanencia en el tiempo ${ }^{36}$. En efecto, cuando este se expide despliega sus efectos en el futuro, con una temporalidad indefinida, para los supuestos fácticos que ingresen dentro de su radio de regulación, comportándose como premisa mayor para los pliegos de condiciones que se confeccionen a su amparo, los cuales vienen a constituir la premisa menor. He allí una diferencia importante entre el pliego tipo obligatorio y el pliego específico: el primero es un reglamento y el segundo, como ya se explicó, es un acto administrativo general, sin perjuicio de que luego se convierta en clausulado contractual.

33 El concepto "pliego tipo" o "pliego de condiciones tipo" hace parte del término genérico "documentos tipo". De hecho, es esta última la expresión utilizada por el parágrafo $7 .{ }^{\circ}$ del artículo 2 de la Ley 1150 de 2007, agregado por el artículo 4 de la Ley 1882 de 2018, y es también la usada por el Decreto 342 de 2019, así como por las resoluciones 1798 de 2019 y 0045 de 2020, expedidas por la Agencia Nacional de Contratación Pública - Colombia Compra Eficiente. Los pliegos tipo son, pues, una especie de documentos tipo, género en el que también caben las minutas tipo de contratos o de otros documentos proferidos en el desarrollo de la actividad contractual. Por tal razón, como el objeto del presente escrito son los pliegos de condiciones, se aludirá preferiblemente al concepto de pliegos de condiciones tipo, en lugar de documentos tipo, por ser este más amplio.

34 Édgar GonZález López, óp. cit., p. 52.

35 Sobre el auge del soft law y la estandarización en el derecho global de la contratación estatal, véase: ÓsCar R. Aguilar ValdeZ, "Fuentes y principios del derecho global de las contrataciones públicas", en Juan Carlos Cassagne (dir.), Tratado general de los contratos públicos, t. II, Buenos Aires: La Ley, 2013, pp. 677-730.

36 El pliego de condiciones tipo corresponde a lo que la doctrina foránea denomina "pliego de condiciones generales", ya que contiene reglas aplicables a varios contratos, a diferencia de los "pliegos de condiciones particulares", que se confeccionan por parte de la Administración para un procedimiento de contratación específico. Miguel S. MaRIENHOFF, Tratado de derecho administrativo, t. III-A, óp. cit., p. 210, ROBERTO Dromi, Licitación pública, óp. cit., pp. 256-258. En similar sentido, se ha afirmado que "En derecho comparado se regulan los pliegos de condiciones generales, los pliegos de condiciones particulares y los pliegos de prescripciones técnicas, como elementos normativos que buscan unificar los criterios y contenidos que presentan las diversas administraciones, nacionales o territoriales, a los particulares, con el fin de que se presenten ofertas que satisfagan los fines de la administración". ÉdGAR GONZÁLEZ LÓPEZ, óp. cit., p. 45. 
En cambio, si el pliego de condiciones tipo se expide solo con una finalidad ilustrativa o pedagógica, como sucedía con varios de los que ha publicado la Agencia Nacional de Contratación Pública - Colombia Compra Eficiente y a los cuales este escrito se referirá más adelante, no es un acto administrativo, ni mucho menos reglamento, pues no decide una situación jurídica, es decir, no produce efectos jurídicos vinculantes, ya que solo incorpora recomendaciones que las entidades estatales podrían tener en cuenta al momento de confeccionar los pliegos de condiciones. Se dice entonces que esta clase de pliegos estándar se puede catalogar como soft law porque es un conjunto de recomendaciones o de pautas no imperativas que, si bien regula conductas, no lo hace con la fuerza de las normas jurídicas tradicionales.

\subsection{Antecedentes del Pliego de CONDiCiOnes tipo obligatorio EN EL ORDENAMIENTO JURÍDICO COLOMBIANO. ESTANDARIZACIÓN FACULTATIVA CON TENDENCIA A LA OBLIGATORIEDAD}

Como se indicó en el numeral anterior, antes de la expedición de la Ley 1882 de 2018, las disposiciones normativas que regulaban el pliego de condiciones se caracterizaban por su gran flexibilidad, es decir, por conceder un amplio grado de libertad a las entidades estatales para construir en cada caso el documento que estableciera las reglas de juego del procedimiento de selección y del contrato, pues se consideraba que era descabellado que las normas legales y reglamentarias albergaran toda la casuística de las modalidades de escogencia que se sirvieran del pliego de condiciones ${ }^{37}$.

Hasta la entrada en vigencia de la mencionada Ley, en 2018, no había enunciados legales que establecieran pliegos de condiciones tipo con carácter obligatorio $^{38}$. Sin embargo, a continuación, se mencionan algunos antecedentes importantes que demuestran la tendencia hacia la estandarización que se advertía desde hacía varios años en el país ${ }^{39}$ :

37 En tal sentido, se afirmaba que "resultaría materialmente imposible que tales preceptos descendiesen a la confección de los precisos contenidos de dichos actos administrativos en cada procedimiento administrativo de selección de contratistas en concreto -cosa que sería propia de las facultades regladas, en las cuales la norma detalla exhaustivamente y $\sin$ dejar margen alguno de valoración a la administración, las particularidades del contenido de la decisión para adoptar en cada supuesto específico-, toda vez que ello solo es viable realizarlo atendiendo a las disímiles necesidades del interés público agenciado por cada entidad pública en particular y a las especiales circunstancias propias de cada específico procedimiento de selección de contratistas". Hugo Alberto Marín HernándeZ, "Naturaleza jurídica de las facultades de la administración...", óp. cit., pp. 3-4).

38 Esta fue la apreciación de una parte de la doctrina. Véase Édgar GONZÁLEZ LóPEZ, óp. cit. pp. 45-46. En similar sentido: José LuIs BENAVIDES, El contrato estatal. Entre el derecho público y

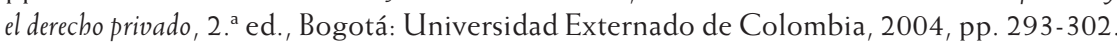

39 Así lo reconoce Barreto Moreno, al expresar, en relación con los pliegos tipo, que: "Esta figura no es novedosa a nivel internacional ni en nuestro medio; entidades públicas del 
a) Puede hallarse un intento de tipificación del pliego en el parágrafo 3 del artículo 2 de la Ley 1150 de 2007, que dispuso que

El Gobierno Nacional tendrá la facultad de estandarizar las condiciones generales de los pliegos de condiciones y los contratos de las entidades estatales, cuando se trate de la adquisición o suministro de bienes y servicios de características técnicas uniformes y de común utilización por parte de las entidades.

b) Posteriormente, el artículo 11, numeral 12, del Decreto 4170 de 2011 -expedido en virtud de las facultades extraordinarias conferidas por el artículo 18 de la Ley 1444 de 2011 - otorgó a la Agencia Nacional de Contratación Pública - Colombia Compra Eficiente-competencia para "Desarrollar e implementar estándares y documentos tipo para las diferentes etapas de la gestión contractual pública". En ejercicio de dicha potestad, la Agencia expidió pliegos modelo o estándar, con carácter facultativo, para procesos de contratación de consultoría $^{40}$, suministro ${ }^{41}$, obra pública ${ }^{42}$ e interventoría ${ }^{43}$.

orden nacional y territoriales habían definido el uso de pliegos tipo en sus procedimientos de selección, es el caso del Instituto Nacional de Vías (Invías) y la ciudad de Bogotá D. C. que ordenó la utilización de los pliegos del Instituto de Desarrollo Urbano a la contratación de las localidades, ambos casos referentes del cambio legislativo. Adicionalmente, la Agencia de Contratación Colombia Compra Eficiente proponía de tiempo atrás la utilización de textos estándar como modelos de contratos, modelos de pliegos de condiciones, proyectos tipo, modelos de documentos del proceso de selección, que en efecto no eran obligatorios, tenían por objeto facilitar la consecución de los documentos y uniformar de esta manera a las entidades públicas en sus procedimientos. Esta experiencia de la agencia es la que utiliza el nivel central para dar cumplimiento a la instrucción del legislativo de expedir estos pliegos". Antonio Alejandro Barreto Moreno, El derecho de la compra pública, Bogotá: Legis - Universidad de la Sabana, 2019, pp. 84-85.

40 Agencia Nacional de Contratación Pública - Colombia Compra Eficiente, Documento publicado el 10 de mayo de 2016. Disponible en línea: https://www.colombiacompra.gov. co/sites/cce_public/files/cce_documents/20150505_pliegocondiciones_contratoconsultoria.pdf [consultado el 17 de febrero de 2020].

41 Agencia Nacional de Contratación Pública - Colombia Compra Eficiente, Documento publicado el 22 de marzo de 2016. Disponible en línea: https://www.colombiacompra. gov.co/sites/cce_public/files/cce_documents/20160322_pliegocondiciones_contratosuministro.pdf [consultado el 17 de febrero de 2020].

42 Agencia Nacional de Contratación Pública - Colombia Compra Eficiente, Documento publicado el 28 de agosto de 2014. Disponible en línea: https://www.colombiacompra.gov.co/ sites/cce_public/files/cce_documents/20140828pliego_de_condiciones_contrato_plan_0. pdf [consultado el 17 de febrero de 2020]. El apéndice de requisitos por habilitante puede consultarse en línea: https://www.colombiacompra.gov.co/sites/cce_public/files/cce_doc uments/20140828apendicecontratosplan_0.pdf [consultado el 17 de febrero de 2020].

43 Agencia Nacional de Contratación Pública - Colombia Compra Eficiente, Documento publicado el 14 de mayo de 2014. Disponible en línea: https://www.colombiacompra. gov.co/sites/cce_public/files/cce_documents/pliego_de_condiciones_interventoria_0. pdf [consultado el 17 de febrero de 2020]. 
c) De igual modo, como antecedentes de los pliegos de condiciones tipo obligatorios, deben mencionarse los documentos estandarizados expedidos por la Agencia Nacional de Contratación Pública - Colombia Compra Eficiente en relación con los denominados "proyectos tipo" ${ }^{\prime 4}$, en el marco del documento Conpes 3856, que incorporó la "estrategia de estandarización de proyectos 2016-2018 ${ }^{\prime \prime 4}$. A estos documentos se les reconoció un grado de obligatoriedad ${ }^{46}$.

\subsection{LA INTRODUCCIÓN DEL PLIEGO DE CONDICIONES TIPO CON CARÁCTER OBLIGATORIO POR LA LEY 1882 DE 2018. CONTENIDO DEL MANDATO LEGAL Y RAZONES QUE LO MOTIVARON: GARANTÍA DE TRANSPARENCIA, LUCHA CONTRA LA CORRUPCIÓN Y CULTURA DE LA ESTANDARIZACIÓN}

El artículo $4 .^{\circ}$ de la Ley 1882 de 2018, por la cual se adicionan, modifican y dictan disposiciones orientadas a fortalecer la Contratación Pública en Colombia, la ley de infraestructura y se dictan otras disposiciones, adicionó el artículo 2 de la Ley 1150 de 2007, incluyendo el parágrafo 7, que establece un mandato dirigido al gobierno para adoptar pliegos tipo ${ }^{47}$. En efecto, según

44 Disponible en línea: https:/www.colombiacompra.gov.co/manuales-guias-y-pliegos-tipo/ dnp [consultado el 17 de febrero de 2020].

45 Consejo Nacional de Política Económica y Social, Documento 3856. Estrategia de estandarización de proyectos 2016-2018. Disponible en línea: https://colaboracion.dnp.gov. co/CDT/Conpes/Econ\%C3\%B3micos/3856.pdf [consultado el 17 de febrero de 2020]. En dicho documento se lee: "Las experiencias internacionales y nacional identifican al menos siete beneficios derivados del uso de proyectos tipo: i) la disminución del tiempo en la formulación de los proyectos; ii) la reducción de los costos en la fase de pre inversión; iii) la provisión de bienes y servicios en igualdad de condiciones para todos los ciudadanos sin importar su localización territorial, iv) la ejecución más ágil y acorde con los tiempos previstos $_{;}$v) la mayor transparencia en la contratación $;$vi) la garantía de un trato igualitario a los interesados en la ejecución de los proyectos, independiente de la entidad estatal que los promueve; y vii) los beneficios económicos y sociales que obtiene la población al disfrutar los proyectos con la oportunidad requerida" (p. 21).

46 Así lo señala el parágrafo del artículo 2.2.6.3.1.1. del Decreto 1082 de 2015: "Siempre que el Departamento Nacional de Planeación disponga de proyectos tipo, las entidades públicas deberán utilizarlos en la etapa de preinversión, incluyendo los pliegos de condiciones y contratos tipo diseñados por Colombia Compra Eficiente para tal efecto. En el evento en que esto no sea viable deberá justificarse y en todo caso tenerse en cuenta dichos insumos para la estructuración integral de los proyectos de inversión".

47 El tenor de la norma es el siguiente: "El Gobierno Nacional adoptará documentos tipo para los pliegos de condiciones de los procesos de selección de obras públicas, interventoría para las obras públicas, interventoría para consultoría de estudios y diseños para obras públicas, consultoría en ingeniería para obras, los cuales deberán ser utilizados por todas las entidades sometidas al Estatuto General de la Contratación de la Administración Pública en los procesos de selección que adelanten. Dentro de los documentos tipo el Gobierno adoptará de manera general y con alcance obligatorio para todas las entidades sometidas al Estatuto General de Contratación de la Administración Pública, las condiciones 
dicha norma, el Gobierno Nacional debe expedir documentos tipo para los pliegos de condiciones que se utilicen en los procedimientos de selección de "obras públicas, interventoría para las obras públicas, interventoría para consultoría de estudios y diseños para obras públicas, [y] consultoría en ingeniería para obras".

Esto significa que, hasta el momento, el deber del Gobierno de expedir pliegos de condiciones tipo no es para todos los procedimientos de selección, sino solo para lo que se establecen en el referido artículo $4 .^{\circ}$ de la Ley 1882 de 2018. Sin embargo, esta misma disposición lo faculta para expedir documentos tipo para otros contratos o modalidades de selección, siendo en este caso una potestad discrecional de dicho organismo.

Ahora bien, en cuanto al contenido de los pliegos de condiciones tipo, según el artículo en comento, estos deberán establecer

las condiciones habilitantes, así como los factores técnicos y económicos de escogencia, según corresponda a cada modalidad de selección y la ponderación precisa y detallada de los mismos, que deberán incluirse en los pliegos de condiciones, teniendo en cuenta la naturaleza y cuantía de los contratos.

Por lo demás, los pliegos de condiciones tipo obligatorios, introducidos en el ordenamiento por la Ley 1882 de 2018, una vez creados por el Gobierno Nacional, solo resultan vinculantes para las entidades sometidas al Estatuto General de Contratación de la Administración Pública, o sea, para aquellas que indica el artículo 2, numeral 1, de la Ley 80 de $1993^{[48]}$; no para las entidades

habilitantes, así como los factores técnicos y económicos de escogencia, según corresponda a cada modalidad de selección y la ponderación precisa y detallada de los mismos, que deberán incluirse en los pliegos de condiciones, teniendo en cuenta la naturaleza y cuantía de los contratos. Para la adopción de esta reglamentación el Gobierno tendrá en cuenta las características propias de las regiones con el ánimo de promover el empleo local. La facultad de adoptar documentos tipo la tendrá el Gobierno Nacional, cuando lo considere necesario, en relación con otros contratos o procesos de selección.

Los pliegos tipo se adoptarán por categorías de acuerdo con la cuantía de la contratación, según la reglamentación que expida el Gobierno Nacional".

48 Según dicho enunciado normativo: "Para los solos efectos de esta ley:

1. ${ }^{\circ}$ Se denominan entidades estatales:

a) La Nación, las regiones, los departamentos, las provincias, el distrito capital y los distritos especiales, las áreas metropolitanas, las asociaciones de municipios, los territorios indígenas y los municipios; los establecimientos públicos, las empresas industriales y comerciales del Estado, las sociedades de economía mixta en las que el Estado tenga participación superior al cincuenta por ciento (50\%), así como las entidades descentralizadas indirectas y las demás personas jurídicas en las que exista dicha participación pública mayoritaria, cualquiera sea la denominación que ellas adopten, en todos los órdenes y niveles.

b) El Senado de la República, la Cámara de Representantes, el Consejo Superior de la Judicatura, la Fiscalía General de la Nación, la Contraloría General de la República, las contralorías departamentales, distritales y municipales, la Procuraduría General de la Nación, la 
exceptuadas ${ }^{49}$, las cuales, sin embargo, pueden adoptarlos discrecionalmente, respetando los límites contenidos en sus reglamentos o manuales internos de contratación.

La razón por la cual se introdujo en el ordenamiento jurídico colombiano la figura del pliego de condiciones tipo con carácter obligatorio fue la necesidad de garantizar el principio de transparencia ${ }^{50}$ en la contratación pública, debido a los múltiples hechos de corrupción que se venían presentando en el país ${ }^{51}$, muchos de los cuales se habían materializado a partir de la elaboración de pliegos de condiciones direccionados o hechos "a la medida" de sujetos determinados ${ }^{52}$. De ahí que se acuñara para esta clase de documentos la denominación de "pliegos sastre" estatal, desde hace algunos años, clamaba por la estandarización del pliego ${ }^{54}$.

Este imperativo de transparencia fue además incluido dentro de las exigencias de la Organización para la Cooperación y el Desarrollo Económico $(\mathrm{OCDE})^{55}$, que, para la época en que se expidió la mencionada Ley 1882, estaba

Registraduría Nacional del Estado Civil, los ministerios, los departamentos administrativos, las superintendencias, las unidades administrativas especiales y, en general, los organismos o dependencias del Estado a los que la ley otorgue capacidad para celebrar contratos".

49 Antonio Alejandro Barreto Moreno, óp. cit., p. 85.

50 Ibíd., p. 85.

51 El Espectador, "Con 'pliegos tipo' buscan frenar corrupción en la contratación de obra pública". 4 de marzo de 2019. Disponible en línea: https://www.elespectador.com/economia/conpliegos-tipo-buscan-frenar-corrupcion-en-la-contratacion-de-obra-publica-articulo-843218 [consultado el 17 de febrero de 2020].

52 Sobre la necesidad de garantizar la transparencia y la lucha contra la corrupción en la contratación pública, véase: LORENZO MELLADO RuIz, El principio de transparencia integral en la contratación del sector público, Valencia: Tirant lo Blanch, 2017, pp. 117-146.

53 En la consulta popular anticorrupción efectuada el 26 de agosto de 2018, la tercera pregunta que se le hizo al pueblo fue: "¿Aprueba usted establecer la obligación a todas las entidades públicas y territoriales de usar pliegos tipo, que reduzcan la manipulación de requisitos habilitantes y ponderables y la contratación a dedo con un número anormalmente bajo de proponentes, en todo tipo de contrato con recursos públicos?", obteniendo 11.428 .985 votos a favor.

54 En tal sentido, González afirmaba: "Resulta indispensable que, en la contratación estatal, después de la complejidad y el número de disposiciones reglamentarias expedidas, derogadas y suspendidas, el Gobierno Nacional adopte pliegos de cláusulas administrativas generales y particulares.

Se busca que los contratos de una misma naturaleza reciban un tratamiento sustancialmente idéntico en el sector público con la seguridad de las reglas aplicables para los comerciantes. La utilidad de este instrumento es innegable, pues otorga claridad y previsibilidad en las reglas sustanciales aplicables al proceso de selección, en beneficio de los intereses generales y particulares". ÉdGAR GONZÁLEZ LÓPEZ, óp. cit., p. 46.

55 En efecto, la OCDE recomendó estandarizar los documentos de la actividad contractual, como forma de asegurar una mayor eficiencia y participación en los procedimientos de compra pública. Al respecto, véase el documento de la OCDE, "Making the Difference in Public Services Delivery: The Review of the Colombian Public Procurement System. Meeting of the Working Party of the Leading Practitioners on Public Procurement", 
analizando la admisibilidad de Colombia en dicho organismo. Por lo cual, el gobierno del presidente de entonces -Juan Manual Santos Calderón- redobló sus esfuerzos para lograr dicho cometido, incorporando la figura del pliego tipo, como una forma de adecuar el sistema de compra pública a los parámetros internacionales ${ }^{56}$.

\subsection{Desarrollo e implementación de los pliegos de Condiciones tipo. Ejercicio "fragmentado" De la potestad Reglamentaria: entre el Gobierno Nacional y Colombia Compra Eficiente}

Tras la promulgación de la Ley 1882 de 2018, el Gobierno Nacional ha optado por implementar parcialmente los pliegos de condiciones tipo, por tipologías contractuales. Así, en lugar de expedir un reglamento que adopte como obligatorios los pliegos tipo para todos los contratos a los que se refiere el parágrafo 7 de la Ley 1150 de 2007, adicionado por el artículo 4 de la Ley 1882 de 2018, el Gobierno ha preferido crear decretos reglamentarios que vayan implementado tales documentos en sectores específicos. Hasta el momento ha proferido dos decretos para hacer obligatorios tales pliegos en materia de infraestructura de transporte ${ }^{57}$-el 342 y el 2096 de 2019-. De igual manera, en ambos ha utilizado la metodología de indicar el contenido mínimo de los

16-17 de diciembre de 2015. Disponible en línea: https://www.colombiacompra.gov.co/ sites/cce_public/files/cce_documentos/the_review_of_the_colombian_public_procurement_system.pdf [consultado el 17 de febrero de 2020].

56 Así lo relataba la Agencia Nacional de Contratación Pública - Colombia Compra Eficiente en sus comunicados de prensa: "Juan David Duque, director de Colombia Compra Eficiente, señaló que entre los beneficios de los pliegos tipo están lograr una mayor participación de contratistas en las licitaciones del Estado lo cual puede impactar en una mejor utilización de los recursos públicos y en mayor competencia. 'Con esta estandarización además de que adoptamos mecanismos internacionales recomendados por la OCDE, las entidades estatales optimizarán los tiempos de planeación de la contratación lo que les permite una mayor organización en sus metas de desarrollo' puntualizó Duque". 23 de noviembre de 2017. Disponible en línea: https://www.colombiacompra.gov.co/sala-de-prensa/comunicados/proyecto-de-pliegos-tipo-fortalecen-la-transparencia-en-el-pais [consultado el 17 de febrero de 2020].

57 El artículo 2 de la Ley 1682 de 2013 dispone: "La infraestructura del transporte es un sistema de movilidad integrado por un conjunto de bienes tangibles, intangibles y aquellos que se encuentren relacionados con este, el cual está bajo la vigilancia y control del Estado, y se organiza de manera estable para permitir el traslado de las personas, los bienes y los servicios, el acceso y la integración de las diferentes zonas del país y que propende por el crecimiento, competitividad y mejora de la calidad de la vida de los ciudadanos". Por su parte, el artículo 4 establece: "La infraestructura de transporte está integrada, entre otros por:

1. La red vial de transporte terrestre automotor con sus zonas de exclusión o fajas de retiro obligatorio, instalaciones operativas como estaciones de pesaje, centros de control de operaciones, estaciones de peaje, áreas de servicio y atención, facilidades y su señalización, entre otras.

2. Los puentes construidos sobre los accesos viales en Zonas de Frontera. 
pliegos tipo, defiriendo su desarrollo e implementación a la Agencia Nacional de Contratación Pública - Colombia Compra Eficiente, en coordinación con el Departamento Nacional de Planeación, lo que ha generado algunas inquietudes sobre su legalidad, como se pondrá de manifiesto más adelante. Por ello se afirma en el título de este apartado que la potestad reglamentaria para la adopción de los pliegos tipo obligatorios se ha ejercido de manera "fragmentada".

En efecto, el Gobierno Nacional expidió el Decreto 342 de 2019, por el cual se adiciona la sección 6 de la subsección 1 del capítulo 2 del título 1 de la parte 2 del libro 2 del Decreto 1082 de 2015, Decreto Único Reglamentario del Sector Administrativo de Planeación Nacional, adoptando los documentos tipo para los pliegos de condiciones en los procesos de licitación de obra

3. Los viaductos, túneles, puentes y accesos de las vías terrestres y a terminales portuarios y aeroportuarios.

4. Los ríos, mares, canales de aguas navegables y los demás bienes de uso público asociados a estos, así como los elementos de señalización como faros, boyas y otros elementos para la facilitación y seguridad del transporte marítimo y fluvial y sistemas de apoyo y control de tráfico, sin perjuicio de su connotación como elementos de la soberanía y seguridad del Estado. 5. Los puertos marítimos y fluviales y sus vías y canales de acceso. La infraestructura portuaria, marítima y fluvial comprende las radas, fondeaderos, canales de acceso, zonas de maniobra, zonas de protección ambiental y/o explotación comercial, los muelles, espigones diques direccionales, diques de contracción y otras obras que permitan el mantenimiento de un canal de navegación, estructuras de protección de orillas y las tierras en las que se encuentran construidas dichas obras.

6. Las líneas férreas y la infraestructura para el control del tránsito, las estaciones férreas, la señalización y sus zonas de exclusión o fajas de retiro obligatorio.

7. La infraestructura logística especializada que contempla los nodos de abastecimiento mayorista, centros de transporte terrestre, áreas logísticas de distribución, centros de carga aérea, zonas de actividades logísticas portuarias, puertos secos y zonas logísticas multimodales.

8. La infraestructura aeronáutica y aeroportuaria destinada a facilitar y hacer posible la navegación aérea.

9. Los Sistemas de Transporte por Cable: teleférico, cable aéreo, cable remolcador y funicular, construidos en el espacio público y/o con destinación al transporte de carga o pasajeros.

10. La infraestructura urbana que soporta sistemas de transporte público, sistemas integrados de transporte masivo, sistemas estratégicos de transporte público y sistemas integrados de transporte público; el espacio público que lo conforman andenes, separadores, zonas verdes, áreas de control ambiental, áreas de parqueo ocasional, así como ciclorrutas, paraderos, terminales, estaciones y plataformas tecnológicas.

11. Redes de sistemas inteligentes de transporte.

Parágrafo $1{ }^{\circ}$. La integración a la que se refiere el presente artículo no modifica las competencias, usos, propiedad o destinación adicionales que el legislador haya previsto respecto de los bienes antes descritos.

Parágrafo 2. ${ }^{\circ}$. Las zonas de exclusión o fajas de retiro obligatorio deberán ser previamente adquiridas por el responsable del proyecto de infraestructura de transporte, cuando se requiera su utilización". 
pública de infraestructura de transporte. La finalidad de este decreto es -según se lee en sus consideraciones- hacer más eficiente y transparente la contratación de obra de infraestructura de transporte en el país. Por ello, en el artículo 2.2.1.2.6.1.1 decide adoptar los pliegos de condiciones tipo en dicho sector, estableciendo en el artículo 2.2.1.2.6.1.2 el alcance o contenido mínimo de dichos documentos y haciéndolos obligatorios para las entidades sometidas al Estatuto General de Contratación de la Administración Pública. Por su parte, en el artículo 2.2.1.2.6.1.3 establece, como se indicó previamente, que la Agencia Nacional de Contratación Pública - Colombia Compra Eficiente sería, junto con el Departamento Nacional de Planeación y el Ministerio de Transporte, la autoridad encargada de desarrollar e implementar los documentos tipo en esta materia. Por otra parte, el artículo 2.2.1.2.6.1.4 consagra la inalterabilidad de los pliegos estándar, al indicar que: "Las entidades estatales contratantes no podrán incluir o modificar dentro de los Documentos del Proceso las condiciones habilitantes, los factores técnicos y económicos de escogencia y los sistemas de ponderación distintos a los señalados en los Documentos Tipo", aspecto que resulta crucial para analizar la permanencia o desaparición de la discrecionalidad administrativa para la confección del pliego de condiciones.

La Agencia Nacional de Contratación Pública - Colombia Compra Eficiente profirió la Resolución 1798 del 1. ${ }^{\circ}$ de abril de 2019, por la cual se desarrollan e implementan los documentos tipo para los procesos de selección de licitación de obra pública de infraestructura de transporte. Esta fue la versión 1 de dichos pliegos tipo ${ }^{58}$. La versión $2^{[59]}$ se adoptó mediante la Resolución 0045 del 14 de febrero de 2020, que derogó en su artículo 3 la Resolución 1798 de 2019. Ello por cuanto la mencionada Agencia consideró necesario actualizar dichos pliegos tipo, para hacerlos más acordes con la realidad de la contratación del país y resolver las múltiples observaciones e inquietudes que se habían hecho explícitas en las consultas formuladas a la Subdirección de Gestión Contractual de dicho organismo ${ }^{60}$. Los principales ajustes de la versión 2 de los pliegos tipo para la licitación de obra pública se infraestructura de transporte se sintetizan así: a) se incorporan reglas para la adaptación del pliego a los casos en que la

58 Agencia Nacional de Contratación Pública - Colombia Compra Eficiente, Pliego de condiciones tipo para licitación de obra pública de infraestructura de transporte. Versión 1. Disponible en línea: https://www.colombiacompra.gov.co/content/version-01 [consultado el 25 de febrero de 2020].

59 Agencia Nacional de Contratación Pública - Colombia Compra Eficiente, Pliego de condiciones tipo para licitación de obra pública de infraestructura de transporte. Versión 2. Disponible en línea: https://www.colombiacompra.gov.co/content/version-02 [consultado el 25 de febrero de 2020].

60 Agencia Nacional de Contratación Pública - Colombia Compra Eficiente, documentos tipo de obra pública de infraestructura de transporte. Comunicado de prensa. Disponible en línea: https://www.colombiacompra.gov.co/sala-de-prensa/comunicados/documentos-tipode-obra-publica-de-infraestructura-de-transporte [consultado el 25 de febrero de 2020]. 
licitación se estructura por lotes o grupos; b) se aclaran las reglas sobre: subsanabilidad, otorgamiento de documentos en el exterior, legitimación para la entrega de las propuestas, publicación del informe de evaluación, acreditación del requisito de la seguridad social por parte de las personas naturales y jurídicas, diligenciamiento del formulario de la propuesta económica y acreditación del puntaje por el criterio de industria nacional ${ }_{i}$ c) se elimina la causal de rechazo de la oferta por la diferencia mayor o igual al $1 \%$ por exceso o por defecto respecto del presupuesto oficial o los precios unitarios establecidos por la entidad pública, d) se incorporan reglas en relación con la visita al sitio de la obra, e) se prevé una nueva regla para la fijación de la tasa representativa del mercado (TRM) como elemento del método de ponderación, pasando de establecerla a partir del día efectivo de la audiencia de adjudicación -como lo señalaba la versión 1 de los documentos tipo-, para determinarla con la del día hábil siguiente a la apertura efectiva del segundo sobre y, si la contratación se realiza por el SECOP II, con la que rija el día de la apertura de los sobres, f) se incrementan los criterios para acreditar el factor de calidad; y g) se incluyen condiciones de asignación y puntaje y desempate para promover el desarrollo social y económico del Departamento Archipiélago de San Andrés, Providencia y Santa Catalina ${ }^{61}$.

El Gobierno Nacional expidió además el Decreto 2096 del 21 de noviembre de 2019, por el cual se adiciona la subsección 2, de la sección 6, del capítulo 2, del título 1, de la parte 2, del libro 2 del Decreto 1082 de 2015, Decreto Único Reglamentario del Sector Administrativo de Planeación Nacional, mediante el cual se adoptan los documentos tipo para los pliegos de condiciones de los procesos de selección abreviada de menor cuantía de obras públicas de infraestructura de transporte. La motivación de este decreto es similar a la del Decreto 342 de 2019, en el sentido de justificar la implementación de los pliegos de condiciones tipo en los procedimientos de selección abreviada de menor cuantía en el mismo sector, por razones de eficiencia y transparencia. Así mismo, llama la atención que en la parte considerativa del Decreto 2096 del 21 de noviembre de 2019 se explique de manera más profunda la competencia de la Agencia Nacional de Contratación Pública Colombia Compra Eficiente para el desarrollo e implementación de dichos pliegos, lo que puede deberse a las discusiones que se han presentado sobre la competencia reglamentaria de dicho organismo o sobre el alcance de sus facultades como ente rector del sistema de compra pública. En tal sentido, el Decreto 2096, al igual que lo hace el 342, encomienda a dicha Agencia la labor de materializar el contenido de los pliegos tipo, como ejecución de su competencia de microrregulación -concepto utilizado por el mismo decreto reglamentario-, actividad que también debe adelantar en coordinación con el Departamento Nacional de Planeación y el Ministerio de Transporte. 
En cumplimiento de esta asignación, la Agencia Nacional de Contratación Pública - Colombia Compra Eficiente expidió la Resolución 004 del 14 de febrero de 2020, por la cual se desarrollan e implementan los documentos tipo para los pliegos de condiciones de los procesos de infraestructura de transporte que se adelanten por la modalidad de selección abreviada de menor cuantía. Los aspectos más destacados de estos pliegos de condiciones son que: a) establecen información general en cuanto al procedimiento de selección, dejando campos que deben ser llenados con la información de cada circunstancia ${ }_{i}$ b) fijan reglas para cuando el proceso se delante por lotes o grupos; c) regulan la regla de la subsanabilidad ${ }_{i}$ d) establecen causales de rechazo; e) prevén las reglas para la elaboración y presentación de la oferta, así como para el cumplimiento de los requisitos habitantes relacionados con aspectos técnicos, jurídicos y financieros; f) señalan los criterios para la evaluación, asignación de puntaje y el desempate; y g) regulan la asignación de los riesgos, los acuerdos comerciales, las garantías, así como la minuta y las condiciones del contrato.

En resumen, los pliegos de condiciones tipo obligatorios que se han expedido hasta ahora, así como el contenido de los mismos, se sintetizan en el siguiente cuadro:

\begin{tabular}{|c|c|c|}
\hline $\begin{array}{l}\text { Decreto } \\
\text { reglamentario del } \\
\text { Gobierno Nacional }\end{array}$ & $\begin{array}{c}\text { Resolución de la Agencia } \\
\text { Nacional de Contratación } \\
\text { Pública - Colombia Compra } \\
\text { Eficiente, expedida en } \\
\text { desarrollo del decreto } \\
\text { reglamentario mencionado en } \\
\text { la columna anterior }\end{array}$ & $\begin{array}{c}\text { Contenido del pliego de condiciones tipo } \\
\text { implementado por la Agencia Nacional de } \\
\text { Contratación Pública - Colombia Compra } \\
\text { Eficiente para concretar el decreto del } \\
\text { Gobierno Nacional }\end{array}$ \\
\hline $\begin{array}{l}\text { Decreto } 342 \text { de } \\
2019 \text {, por el cual se } \\
\text { adiciona la sección } 6 \\
\text { de la subsección } 1 \text { del } \\
\text { capítulo } 2 \text { del título } 1 \\
\text { de la parte } 2 \text { del libro } \\
2 \text { del Decreto } 1082 \\
\text { de } 2015 \text {, Decreto } \\
\text { Único Reglamentario } \\
\text { del Sector } \\
\text { Administrativo de } \\
\text { Planeación Nacional }\end{array}$ & $\begin{array}{l}\text { Resolución } 1798 \text { del } 1 .{ }^{\circ} \text { de } \\
\text { abril de } 2019 \text {, por la cual se } \\
\text { desarrollan e implementan } \\
\text { los documentos tipo para } \\
\text { los procesos de selección de } \\
\text { licitación de obra pública de } \\
\text { infraestructura de transporte } \\
\text { (versión } 1 \text { ). }\end{array}$ & $\begin{array}{l}\text { Documento base o pliegos tipo } \\
\text { Anexo 1. Anexo técnico } \\
\text { Anexo 2. Cronograma } \\
\text { Anexo 3. Glosario } \\
\text { Anexo 4. Pacto de transparencia } \\
\text { Anexo 5. Minuta del contrato } \\
\text { Formato 1. Carta de presentación de la oferta } \\
\text { Formato 2. Conformación del proponente } \\
\text { plural } \\
\text { Formato 3. Experiencia } \\
\text { Formato 4. Capacidad financiera y } \\
\text { organizacional extranjeros } \\
\text { Formato 5. Capacidad residual } \\
\text { Formato 6. Pago de seguridad social y aportes } \\
\text { legales } \\
\text { Formato 7. Factor calidad } \\
\text { Formato 8. Vinculación de personas con } \\
\text { discapacidad } \\
\text { Formato 9. Puntaje de industria nacional } \\
\text { Formulario 1. Formulario de presupuesto oficial } \\
\text { Matriz 1. Experiencia } \\
\text { Matriz 2. Indicadores financieros y } \\
\text { organizacionales } \\
\text { Matriz 3. Riesgos }\end{array}$ \\
\hline
\end{tabular}




\begin{tabular}{|c|c|c|}
\hline & $\begin{array}{l}\text { Resolución } 0045 \text { del } 14 \\
\text { de febrero de } 2020 \text {, por } \\
\text { la cual se actualizan los } \\
\text { documentos tipo para los } \\
\text { procesos de selección de } \\
\text { licitación de obra pública de } \\
\text { infraestructura de transporte } \\
\text { y se deroga la Resolución } \\
1798 \text { de } 2019 \text { (corresponde } \\
\text { a la versión } 2 \text { de los pliegos } \\
\text { de condiciones tipo para } \\
\text { licitación de obra pública de } \\
\text { infraestructura de transporte) }\end{array}$ & $\begin{array}{l}\text { Documento base o pliegos tipo } \\
\text { Anexo 1. Anexo técnico } \\
\text { Anexo 2. Cronograma } \\
\text { Anexo 3. Glosario } \\
\text { Anexo 4. Pacto de transparencia } \\
\text { Anexo 5. Minuta del contrato } \\
\text { Formato 1. Carta de presentación de la oferta } \\
\text { Formato 2. Conformación del proponente } \\
\text { plural } \\
\text { Formato 3. Experiencia } \\
\text { Formato 4. Capacidad financiera y } \\
\text { organizacional extranjeros } \\
\text { Formato 5. Capacidad residual } \\
\text { Formato 6. Pago de seguridad social y aportes } \\
\text { legales } \\
\text { Formato 7. Factor calidad } \\
\text { Formato 8. Vinculación de personas con } \\
\text { discapacidad } \\
\text { Formato 9. Puntaje de industria nacional } \\
\text { Formulario 1. Formulario de presupuesto oficial } \\
\text { Matriz 1. Experiencia } \\
\text { Matriz 2. Indicadores financieros y } \\
\text { organizacionales } \\
\text { Matriz 3. Riesgos }\end{array}$ \\
\hline $\begin{array}{l}\text { Decreto } 2096 \text { del } \\
21 \text { de noviembre } \\
\text { de } 2019 \text {, por el } \\
\text { cual se adiciona } \\
\text { la subsección 2, } \\
\text { de la sección 6, } \\
\text { del capítulo 2, del } \\
\text { título 1, de la parte } \\
\text { 2, del libro } 2 \text { del } \\
\text { Decreto } 1082 \text { de } \\
\text { 2015, Decreto Único } \\
\text { Reglamentario } \\
\text { del Sector } \\
\text { Administrativo de } \\
\text { Planeación Nacional }\end{array}$ & $\begin{array}{l}\text { Resolución } 004 \text { del } 14 \text { de } \\
\text { febrero de } 2020 \text {, por la cual } \\
\text { se desarrollan e implementan } \\
\text { los documentos tipo para los } \\
\text { pliegos de condiciones de los } \\
\text { procesos de infraestructura de } \\
\text { transporte que se adelanten } \\
\text { por la modalidad de selección } \\
\text { abreviada de menor cuantía }\end{array}$ & $\begin{array}{l}\text { Documento base o pliegos tipo } \\
\text { Anexo 1. Anexo técnico } \\
\text { Anexo 2. Cronograma } \\
\text { Anexo 3. Glosario } \\
\text { Anexo 4. Pacto de transparencia } \\
\text { Anexo 5. Minuta del contrato } \\
\text { Formato 1. Carta de presentación de la oferta } \\
\text { Formato 2. Conformación del proponente } \\
\text { plural } \\
\text { Formato 3. Experiencia } \\
\text { Formato 4. Capacidad financiera y } \\
\text { organizacional extranjeros } \\
\text { Formato 5. Capacidad residual } \\
\text { Formato 6. Pago de seguridad social y aportes } \\
\text { legales } \\
\text { Formato 7. Factor calidad } \\
\text { Formato 8. Vinculación de personas con } \\
\text { discapacidad } \\
\text { Formato 9. Puntaje de industria nacional } \\
\text { Formato 10. Carta de manifestación de interés } \\
\text { Formulario 1. Formulario de presupuesto oficial } \\
\text { Matriz 1. Experiencia } \\
\text { Matriz 2. Indicadores financieros y } \\
\text { organizacionales } \\
\text { Matriz 3. Riesgos }\end{array}$ \\
\hline
\end{tabular}




\subsection{Discusión sobre la competencia de la Agencia Nacional de Contratación Pública - Colombia Compra Eficiente para el desarrollo E IMPLEMENTACIÓN DE LOS PLIEGOS DE CONDICIONES TIPO PREVISTOS EN EL ARTÍCULO 4 DE LA LEY 1882 DE 2018}

Según se indicó, tanto el Decreto 342 de 2019, como el 2096 del mismo año, expedidos por el Gobierno Nacional, han encomendado a la Agencia Nacional de Contratación Pública -Colombia Compra Eficiente, en coordinación con el Departamento Nacional de Planeación y el Ministerio de Transporte, el desarrollo e implementación de los pliegos de condiciones tipo obligatorios para los procedimientos de licitación y selección abreviada de menor cuantía de infraestructura de transporte. La discusión que se ha generado en cuanto a este aspecto se resume en el siguiente interrogante: ¿podía el Gobierno dejar en manos de dicha Agencia el desarrollo e implementación de los pliegos de condiciones tipo, a pesar de que el artículo $4 .^{\circ}$ de la Ley 1882 de 2018 le otorgó expresamente a aquel la competencia ${ }^{62}$ y de que el artículo 189 numeral 11 de la Constitución le confiere a este la potestad reglamentaria para la cumplida ejecución de las leyes?

El Decreto-Ley 4170 de 2011, por el cual se crea la Agencia Nacional de Contratación Pública - Colombia Compra Eficiente, se determinan sus objetivos y estructura, establece como competencia de la Subgerencia de Gestión Contractual de dicha entidad "Desarrollar e implementar estándares y documentos tipo para las diferentes etapas de la gestión contractual pública"63. De otro lado, el artículo 2.2.1.2.5.2 del Decreto 1082 de 2015, en su numeral 3, le asigna a Colombia Compra Eficiente competencia para la elaboración de "Pliegos de condiciones tipo para la contratación"64.

En tal sentido, una posible interpretación es que tal Agencia ostenta la competencia para desarrollar e implementar los pliegos de condiciones tipo a los que se refiere el artículo $4 .^{\circ}$ de la Ley 1882 de 2018, porque otra norma de carácter legal le asigna dicha potestad. Una segunda interpretación es que, al disponer este último artículo que es competencia del Gobierno Nacional

62 En efecto, el artículo 4 de la Ley 1882 de 2018, que adicionó el parágrafo $7 .^{\circ}$ al artículo 2 de la Ley 1150 de 2007, utiliza las siguientes expresiones: "el Gobierno Nacional adoptará documentos tipo" y "La facultad de adoptar documentos tipo la tendrá el Gobierno Nacional".

63 Decreto 4170 de 2011, artículo 11, numeral 12.

64 Aunque, mediante sentencia del 11 de abril de 2019 (Sección Tercera, Radicación 11001 03-26-000-2014-00135-00, Expediente 52055), el Consejo de Estado declaró la nulidad del numeral 3 del artículo 159 del Decreto 1510 de 2013, derogado por el artículo 2.2.1.2.5.2., numeral 3, del Decreto 1082 de 2015, que lo reproduce literalmente, se considera que la norma del Decreto 1082 no puede entenderse anulada y actualmente se presume legal, de conformidad con lo establecido en el artículo 88 de la Ley 1437 de 2011. 
adoptar los documentos tipo, derogó tácitamente el artículo 11, numeral 12, del Decreto 4170 de 2011 que le otorgaba dicha facultad a la Agencia.

En la sentencia del 11 de abril de 2019 de la Sección Tercera del Consejo de Estado se decantó por la idea de que, en el ordenamiento jurídico, la potestad reglamentaria no es exclusiva del presidente de la república, sino que existen otras autoridades que cuentan con dicha competencia y que, para compaginar su ejercicio, debe atenderse a los principios de jerarquía y distribución de competencias. Pero también aclaró que el presidente no puede delegar su función reglamentaria permanente en otras autoridades ${ }^{65}$. En este orden de ideas, Colombia Compra Eficiente, como órgano rector del sistema de contratación pública, goza de potestad reglamentaria subordinada a la del presidente; es decir, de una potestad de segundo grado.

Bajo esta perspectiva, de las dos posibles interpretaciones planteadas anteriormente, se acoge la primera, es decir, que el artículo $4 .^{\circ}$ de la Ley 1882 de 2018 no implicó una derogación del artículo 11, numeral 12 del Decreto 4170 de 2011 y que, por ende, en la actualidad la Agencia Nacional de Contratación Pública - Colombia Compra Eficiente goza de competencia para implementar y desarrollar mediante reglamentos de segundo grado los pliegos de condiciones tipo adoptados por el presidente de la república en reglamentos de primer grado, expedidos estos últimos en ejercicio de la potestad conferida por el artículo 189 numeral 11 de la Constitución. En otras palabras, la competencia del organismo rector del sistema de contratación pública solo se activa cuando el presidente de la república ha expedido el reglamento que implementa el pliego de condiciones tipo. De lo contrario, la Agencia no lo puede expedir con carácter vinculante, aunque sí podría adoptarlo con carácter facultativo.

\section{DOCUMENTOS TIPO OBLIGATORIOS Y REDUCCIÓN DE LA DISCRECIONALIDAD ADMINISTRATIVA PARA LA CONFECCIÓN DEL PLIEGO DE CONDICIONES ESPECÍFICO}

Según se expresó, la libertad de la Administración para la elaboración del pliego de condiciones no es absoluta, ya que encuentra límites en los elementos reglados del acto administrativo, en la finalidad de interés general a la que debe atender y en el principio de proporcionalidad ${ }^{66}$. De ahí que se haya

65 Consejo de Estado, Sección Tercera, sentencia del 11 de abril de 2019, radicación 11001 03-26-000-2014-00135-00, expediente 52055.

66 En palabras de la Sección Tercera del Consejo de Estado, la Administración cuenta con autonomía o discrecionalidad para la elaboración del pliego de condiciones "siempre y cuando no se establezcan reglas caprichosas que desconozcan las normas de orden público, con fundamento en el principio de la proporcionalidad, como instrumento que dota de razonabilidad el ejercicio de las competencias de la administración, y que se encuentra presente en todo el ámbito de la actividad estatal, del que forma parte la contratación 
dicho que no existen, pues, actos absolutamente reglados, ni absolutamente discrecionales ${ }^{67}$.

Ahora bien, lo cierto es que, como se vio, la figura del pliego de condiciones tipo obligatorio limita en grado sumo la discrecionalidad de las entidades estatales para la confección del pliego de condiciones específico ${ }^{68}$. Pero de allí no puede colegirse que tal discrecionalidad desaparezca. Aunque más reducida por el conjunto de cláusulas del pliego de condiciones tipo, que se impone a las entidades estatales, estas aún cuentan con un margen de apreciación para determinar la mejor forma de satisfacer el interés general al momento de confeccionar el pliego de condiciones para los procedimientos de selección que adelanten, pues el documento estándar adoptado por el Gobierno Nacional e implementado por la Agencia Nacional de Contratación Pública - Colombia Compra Eficiente, por más que quisiera, no puede -ni debe- llegar hasta el más mínimo detalle de la actividad contractual de las entidades públicas.

En efecto, incluso con los pliegos de condiciones tipo que son obligatorios actualmente -en las licitaciones y selecciones abreviadas de menor cuantía para la celebración de contratos de obra pública de infraestructura de transporte-, las entidades estatales cuentan con discrecionalidad para: a) decidir si con$\operatorname{tratan}_{i}$ b) determinar el objeto, plazo, valor y lugar de ejecución del contrato, de conformidad con los estudios previos; c) establecer si desean estructurar

pública". Consejo de Estado, Sección Tercera, sentencia del 31 de mayo de 2019, radicación 11001-03-26-000-2011-00065-00, expediente 42282. En similar orientación, véase: Consejo de Estado, Sección Tercera, sentencia del 13 de agosto de 2014, radicación: 2500023-26-000-2004-01200-01, expediente 35965. De igual manera, la doctrina ha señalado que, si bien las entidades estatales cuentan con discrecionalidad para la elaboración del pliego de condiciones, deben hacerlo respetando el principio de proporcionalidad. Huco Alberto Marín Hernández, El principio de proporcionalidad en el derecho administrativo colombiano, Bogotá: Universidad Externado de Colombia, 2018, pp. 45-47. En similar sentido, ROBERTO Dromi, Licitación pública, óp. cit., pp. 250-251.

67 Cristian Díaz Díez, óp. cit., pp. 342-345. En igual sentido: Miguel S. Marienhoff, Tratado de derecho administrativo, t. II, óp. cit., p. 425. Por su parte, la imposibilidad de confundir la discrecionalidad con la arbitrariedad en la contratación estatal puede leerse en JUAN CARLOS EXPÓSITO VÉLEZ, "Autonomía de la voluntad, competencias regladas y discrecionales en el contrato estatal", en Héctor Santaella Quintero (ed.), Las transformaciones de la Administración pública y del derecho administrativo, $t$. II, La reinvención de los instrumentos jurídicos y materiales utilizados por la Administración, Bogotá: Universidad Externado de Colombia, 2019, p. 128.

68 "La amplia facultad creada por el legislador le permite al Gobierno Nacional expedir un detallado pliego de condiciones que podría incluir todos los aspectos de planeación y selección exigidos por la norma superior, como estudios de mercado, de sector, análisis de precios, restricciones presupuestales, condiciones técnicas y obviamente jurídicas, que tendrán por fin o efecto restringir o ampliar la competencia del mercado regulado. Quizá con esta norma, el manual de contratación de las entidades sometidas al régimen general se limita a su mínima expresión, las observaciones al pliego ya no se harán ante la entidad contratante, sino ante el Gobierno Nacional". Antonio Alejandro Barreto Moreno, óp. cit., pp. 86-87. 
o no el proceso por grupos o lotes; d) fijar el cronograma del proceso según las disposiciones legales y reglamentarias; e) definir qué experiencia solicitar como requisito habilitante o criterio de evaluación, respetando las directrices del pliego tipo; g) señalar, según su justificación de necesidad en los estudios previos, si es conducente la visita al sitio de ejecución de la obra; ${ }_{i}$ ) indicar si la forma de pago será por "precio global, llave en mano, precios unitarios, administración delegada o reembolso de gastos ${ }^{169}{ }_{i}$ h) elegir una entre varias opciones para la asignación de puntaje por el factor de calidad ${ }_{i}$ e i) establecer si deciden o no entregar anticipo o pago anticipado, entre otros aspectos.

Por lo tanto, teniendo claro que la adopción de los pliegos de condiciones tipo obligatorios no supone una supresión de la discrecionalidad administrativa de las entidades estatales para la confección de sus pliegos particulares, aunque sí les impone límites adicionales a los que ya las disposiciones legales y reglamentarias señalaban, la cultura de la estandarización de los documentos contractuales debe analizarse críticamente, para determinar las ventajas y desventajas de su carácter vinculante, no solo en el marco de la lucha contra la corrupción, sino también de cara a la autonomía de los entes territoriales, a la autonomía de la voluntad reconocida a los órganos del Estado para contratar y a las necesidades concretas de cada proyecto que dificultan el establecimiento de reglas generales que restrinjan la solicitud de exigencias más estrictas para asegurar la calidad de los bienes o servicios requeridos por las entidades estatales.

Si bien la lucha contra la corrupción ha hecho necesaria la implementación de medidas que impidan prácticas indeseables como el direccionamiento de los pliegos de condiciones, el establecimiento de documentos tipo no puede suprimir la discrecionalidad de las entidades estatales para la configuración de sus pliegos en cada caso, pues son ellas las que conocen en mayor medida sus necesidades contractuales. Además, no se puede partir de la mala fe, para suponer que la discrecionalidad dará paso al "pliego sastre". La estandarización, en consecuencia, no puede ser un fin en sí mismo, sino una estrategia aplicada también proporcionalmente, en respeto de la distribución de competencias, las exigencias de calidad y la libertad económica.

\section{CONCLUSIONES}

A pesar de la adopción e implementación de pliegos de condiciones tipo con carácter obligatorio para ciertos procedimientos de selección, la labor de confección de los pliegos de condiciones específicos por parte de las

69 Ver numeral 4.1. de Agencia Nacional de Contratación Pública - Colombia Compra Eficiente, Pliego de condiciones tipo para licitación de obra pública de infraestructura de transporte. Versión 2. Disponible en línea: https://www.colombiacompra.gov.co/content/ version-02 [consultado el 25 de febrero de 2020]. 
entidades estatales continúa siendo el ejercicio de una potestad discrecional, que debe ejercerse de manera "adecuada a los fines de la norma que la autoriza, y proporcional a los hechos que le sirven de causa" ${ }^{170}$, y cumpliendo con los elementos reglados que siempre están presentes al momento de expedir los actos administrativos.

La Agencia Nacional de Contratación Pública - Colombia Compra Eficiente cuenta con potestad reglamentaria de segundo grado para desarrollar e implementar los pliegos de condiciones tipo que establezca como obligatorios el presidente de la república en reglamentos de primer grado. De este modo, los pliegos tipo vinculantes expedidos por dicha Agencia son reglamentos secundum legem, en la medida en que se trata de actos administrativos de carácter general, que gozan de vocación de permanencia en el tiempo, porque regulan los procedimientos de selección que versen sobre las tipologías que la ley y el reglamento hayan establecido como supuestos de aplicación de los pliegos tipo, comportándose así como límites reglamentarios al ejercicio de la discrecionalidad administrativa para la elaboración de los pliegos específicos.

Pero la estandarización de los pliegos de condiciones y, en general, de los documentos contractuales admite un análisis crítico, pues si bien se justifica que existan controles sobre la actividad de adquisición de los bienes y servicios por parte de las entidades estatales para garantizar la transparencia, la tipificación del clausulado del pliego y de los formatos anexos debe ser moderada, para no atentar contra la autonomía de la voluntad, la libertad económica y las exigencias de calidad del objeto contractual.

\section{BIBLIOGRAFÍA}

\section{DOCTRINA}

Aguilar Valdez, Óscar R. "Fuentes y principios del derecho global de las contrataciones públicas". En Juan Carlos Cassagne (dir.), Tratado general de los contratos públicos, t. II (pp. 677-730). Buenos Aires: La Ley, 2013.

Ariño Ortiz, Gaspar. "El enigma del contrato administrativo". En Juan Carlos Cassagne (dir.), Tratado general de los contratos públicos, t. I (pp. 59-87). Buenos Aires: La Ley, 2013.

Barra, Rodolfo Carlos. "Los actos administrativos coligados en el contrato administrativo". En Juan Carlos Cassagne (dir.), Tratado general de los contratos públicos, t. I (pp. 177-240). Buenos Aires: La Ley, 2013. 
Barreto Moreno, Antonio Alejandro. El derecho de la compra pública. Bogotá: Legis Universidad de la Sabana, 2019.

BenAVIDES, José Luis. El contrato estatal. Entre el derecho público y el derecho privado, 2. ${ }^{\text {a }}$ ed. Bogotá: Universidad Externado de Colombia, 2004.

BerçAitz, Miguel Ángel. Teoría general de los contratos administrativos. Buenos Aires: Depalma, 1980 .

Bocanegra Sierra, Raúl. Lecciones sobre el acto administrativo, 3. a ed. Madrid: Thomson Civitas, 2006.

Cassagne, Juan Carlos. El principio de legalidad y el control judicial de la discrecionalidad administrativa. Madrid: Marcial Pons, 2009.

Corvalán, Juan Gustavo. Derecho administrativo en transición. Reconfiguración de la relación entre la Administración, las normas y el Poder Judicial. Reglas y principios. Discrecionalidad débil y fuerte. Valoración, interpretación y ponderación. Control judicial y políticas públicas. Buenos Aires: Astrea, 2016.

Dávila Vinueza, Luis Guillermo. Régimen jurídico de la contratación estatal, 3. a ed. Bogotá: Legis, 2016.

Desdentado Daroca, Eva. Los problemas del control judicial de la discrecionalidad técnica. Un estudio crítico de la jurisprudencia. Madrid: Civitas, 1997.

DíAz DíEz, CRISTIAn. La jurisdicción de lo contencioso administrativo. El control jurisdiccional especializado de la Administración pública dentro del Estado de derecho y la democracia. Medellín: Librería Jurídica Sánchez - Universidad de Antioquia - Centro de Estudios de Derecho Administrativo, 2013.

Dromi, Roberto. Acto administrativo, 4. ${ }^{\text {a }}$ ed. Buenos Aires: Ediciones Ciudad Argentina, Madrid - México: Hispania Libros, 2008.

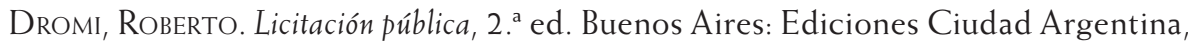
1995.

Duque Botero, Juan David. Contratación pública estratégica, socialmente responsable y competitiva. Valencia: Tirant lo Blanch; Bogotá: Universidad del Rosario, 2018.

Expósito Vélez, Juan Carlos. "Autonomía de la voluntad, competencias regladas y discrecionales en el contrato estatal". En Héctor Santaella Quintero (ed.), Las transformaciones de la Administración pública y del derecho administrativo, t. II, La reinvención de los instrumentos jurídicos y materiales utilizados por la Administración (pp. 109-165). Bogotá: Universidad Externado de Colombia, 2019. 
García de Enterría, Eduardo. La lucha contra las inmunidades del poder en el derecho administrativo. Poderes discrecionales, poderes de gobierno, poderes normativos, $3 .^{a}$ ed. Madrid: Civitas, 1995.

GONZÁLEZ LÓPEZ, ÉDGAR. El pliego de condiciones en la contratación estatal. La reforma consagrada en la Ley 1150 de 2007 y sus decretos reglamentarios. Bogotá: Universidad Externado de Colombia, 2010.

Kuhn, Thomas. La estructura de las revoluciones científicas. México: Fondo de Cultura Económica, 1971.

Marienhoff, Miguel S. Tratado de derecho administrativo, t. II. Actos de la Administración pública, 4ª ed. Buenos Aires: Abeledo-Perrot, 1993.

Marienhoff, Miguel S. Tratado de derecho administrativo, t. III-A. Contratos administrativos. De los contratos en particular, 4. ${ }^{a}$ ed. Buenos Aires: Abeledo-Perrot, 1998.

Marín Hernández, Hugo Alberto. "Naturaleza jurídica de las facultades de la administración para confeccionar pliegos de condiciones". Revista digital de Derecho Administrativo, n. ${ }^{\circ}$ 1, Universidad Externado de Colombia, 2009, pp. 1-18.

Marín Hernández, Hugo Alberto. Discrecionalidad administrativa. Bogotá: Universidad Externado de Colombia, 2007.

Marín Hernández, Hugo Alberto. El principio de proporcionalidad en el derecho administrativo colombiano. Bogotá: Universidad Externado de Colombia, 2018,

Massimo, Leonardo F. "Los pliegos de bases y condiciones". En Juan Carlos Cassagne (dir.), Tratado general de los contratos públicos, t. II (pp. 881-943). Buenos Aires: La Ley, 2013.

Matallana Camacho, ERnesto. "La preservación de las garantías constitucionales en la licitación en el trámite de evaluación de las propuestas y el control que ejerce el juez sobre la actividad contractual de la Administración pública". En Julián Andrés Pimiento Echeverri (ed.), Las transformaciones de la Administración pública y del derecho administrativo, t. III, Las dimensiones del control sobre la actividad administrativa (pp. 71-130). Bogotá: Universidad Externado de Colombia, 2019.

Maurer, Harmut. Derecho administrativo. Parte general, 17. . ed. Madrid: Marcial Pons, 2011.

Mellado Ruiz, LoRenzo. El principio de transparencia integral en la contratación del sector público. Valencia: Tirant lo Blanch, 2017.

Rodríguez De Santiago, José María. Metodología del derecho administrativo. Reglas de racionalidad para la adopción y el control de la decisión administrativa. Madrid: Marcial Pons, 2016. 
Jurisprudencia de la Corte Constitucional

Sentencia C-071 del 23 de febrero de 1994, expediente D-380.

Sentencia T-154 del 28 de abril de 1998, expediente T-150254.

Sentencia T-288 del 4 de junio de 1998, expediente T-156679.

Sentencia C-734 del 21 de junio de 2000, expediente D-2732.

Sentencia C-918 del 29 de octubre de 2002, expediente D-3996.

Sentencia T-1094 del 5 de diciembre de 2002, expediente T-592228.

Sentencia SU-713 del 23 de agosto de 2006, expediente T-851356.

Sentencia T-373 del 11 de mayo de 2007, expediente T-1535128.

Sentencia C-553 del 6 de julio de 2010, expediente D-7951.

Sentencia T-686 del 11 de septiembre de 2014, expediente T-4.346.728.

Sentencia SU-172 del 16 de abril de 2015, expediente T-4.076.348.

Jurisprudencia del Consejo de Estado

Sección Tercera, sentencia del 30 de diciembre de 2006, radicación 11001-03-26000-2000-00020-01, expediente 18059.

Sección Tercera, auto del 30 de agosto de 2008, radicación: 70001-23-31-000-199706303-01, expediente 23003.

Sección Tercera, sentencia del 13 de agosto de 2014, radicación: 25000-23-26-0002004-01200-01, expediente 35965.

Sección Tercera, sentencia del 28 de mayo de 2015, radicación 41001-23-31-0001995-08008-01, expediente 29661.

Sección Tercera, sentencia del 30 de julio de 2015, radicación 25000-23-26-0001999-00242-01, expediente 25296.

Sección Tercera, sentencia del 30 de julio de 2015, radicación 25000-23-26-0001997-13723-01, expediente 29942.

Sección Tercera, sentencia del 3 de septiembre de 2015, radicación 25000-23-26000-2002-01433-01, expediente 33790. 
Sección Tercera, sentencia del 1. ${ }^{\circ}$ de octubre de 2015, radicación: 25000-23-26-0002005-00214-01, expediente 34778.

Sección Tercera, sentencia del 26 de noviembre de 2015, radicación 85001-23-31000-2011-00109-01, expediente 51376.

Sección Tercera, sentencia del 3 de diciembre de 2015, radicación 76001-23-31-0002000-00785-01, expediente 31915.

Sección Tercera, sentencia del 10 de febrero de 2016, radicación 25000-23-26-0002003-00959-01, expediente 38696.

Sección Tercera, sentencia del 29 de febrero de 2016, radicación 25000-23-26-0001999-02474-02, expediente 32141.

Sección Tercera, sentencia del 30 de junio de 2016, radicación 25000-23-26-0001998-02425-01, expediente 34652.

Sección Tercera, sentencia del 2 de marzo de 2017, radicación 25000-23-26-0001997-03892-01, expediente 36442.

Sección Tercera, sentencia del 5 de abril de 2017, radicación 25000-23-26-000-200100309-01, expediente 35163B.

Sección Tercera, sentencia del 18 de mayo de 2017, radicación 05001-23-31-0002010-01243-01, expediente 54480.

Sección Tercera, sentencia del 21 de septiembre de 2017, radicación 25000-23-26000-2001-02144-01, expediente 37478.

Sección Tercera, sentencia del 27 de noviembre de 2017, radicación 08001-23-31000-1998-02160-01, expediente 58362.

Sección Tercera, sentencia del 7 de diciembre de 2017, radicación 25000-23-26-0002007-00059-01, expediente 41888.

Sección Tercera, auto del 19 de julio de 2018, radicación 11001-03-26-000-201700151-00, expediente 60291.

Sección Tercera, sentencia del 2 de agosto de 2018, radicación 25000-23-36-0002013-01293-01, expediente 53506A.

Sección Tercera, auto del 2 de abril de 2019, radicación 11001-03-26-000-201800097-00, expediente 61964.

Sección Tercera, sentencia del 11 de abril de 2019, radicación 11001-03-26-0002014-00135-00, expediente 52055. 
Sección Tercera, sentencia del 31 de mayo de 2019, radicación 11001-03-26-0002010-00077-00, expediente 39961

Sección Tercera, sentencia del 31 de mayo de 2019, radicación 11001-03-26-0002011-00065-00, expediente 42282.

Sección Tercera, sentencia del 5 de agosto de 2019, radicación 25000-23-26-0002009-00264-01, expediente 45118.

Sección Tercera, sentencia del 30 de septiembre de 2019, radicación 25000-23-26000-2009-01040-01, expediente 46733.

Sección Tercera, sentencia del 25 de octubre de 2019, radicación 66001-23-31-0002004-00668 02, expediente 37862 .

Sección Tercera, sentencia del 25 de octubre de 2019, radicación 25000-23-26-0002007-00677-01, expediente 39945. 